\title{
Retablos itinerantes. El paso de Cristo en la Semana Santa de Sevilla
}

RODA PEÑA, José

Diputación de Sevilla, Sevilla, 2016

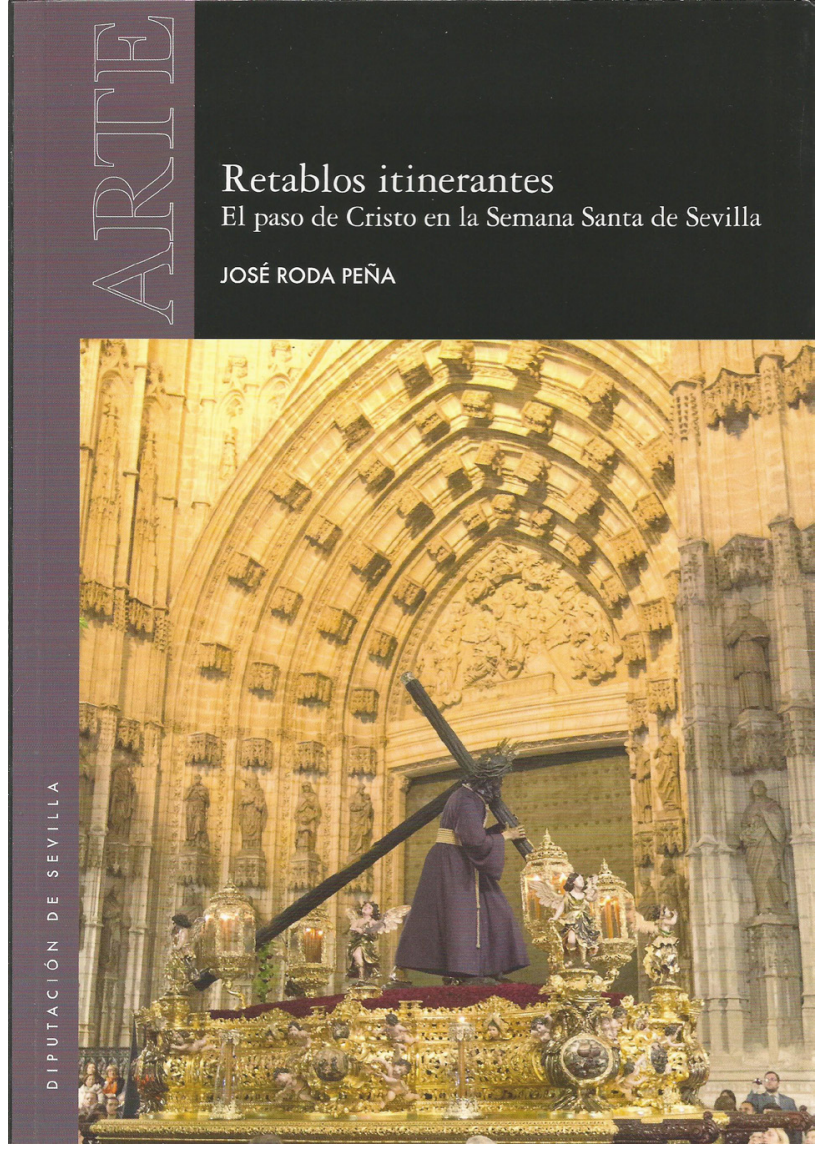

El paso procesional sevillano o el trono malagueño son obras de arte que adquirieron gran desarrollo en los siglos del Barroco con el objeto de trasladar las imágenes por las calles de los pueblos y de las ciudades siguiendo los postulados de la Iglesia católica acordados en el Concilio de Trento. Arquitectos, ensambladores, escultores, tallistas, pintores, doradores y plateros intervinieron en su producción, y algunas obras no valoradas suficientemente fueron una parte importante de la creación barroca. En Sevilla, las sencillas andas con varales derivaron a complejas estructuras con decoración escultórica denominadas paso procesional, en el que los costaleros se ocultan bajo ese conjunto arquitectónico móvil. El proceso de enriquecimiento artístico del paso surgió a partir de mediados del siglo XVII. En algunos documentos se denomina «urna» o "tarima» y actualmente también "canasto». Este elemento mobiliario del patrimonio artístico tuvo un importante desarrollo y diseño creativo en Sevilla con la participación de arquitectos-ensambladores, como Francisco Dionisio de Ribas, Bernardo Simón de Pineda y Cristóbal de Guadix, y escultores como Pedro Roldán, Francisco Antonio Gijón, Luisa Roldán, La Roldana, y su marido Luis Antonio de los Arcos. Estas arquitecturas con relieves alusivos al mensaje cristiano de la Pasión de Jesús fueron concebidas por estos artistas como retablos itinerantes, cuya metáfora ha sido elegida por el autor para el título de este libro.

En el transcurso de los siglos las hermandades y cofradías penitenciales o de gloria han experimentado cambios organizativos y han renovado su patrimonio artístico con frecuencia, por lo que apenas se conservan ejemplares completos del siglo XVII. Como ampliamente analiza José Roda, una de las joyas es el paso de Jesús del Gran Poder diseñado y tallado entre 1688 y 1692 por el escultor Francisco Antonio Gijón, conocido autor del Cristo de la Expiración o El Cachorro. Este autor construyó el paso sesenta años después de que Juan de Mesa tallara la imagen de Jesús con la cruz a cuestas. Desde mediados del siglo XVII se ha producido un número elevado de pasos, que en la mayoría de los casos fueron sustituyendo obras anteriores por el cambio de los gustos estéticos o por el deficiente estado de conservación. Este elemento artístico, poco valorado, forma parte importante del patrimonio cultural andaluz como refleja la vigencia de la manifestación procesional que la Iglesia católica y las asociaciones religiosas mantienen especialmente en la Semana Santa.

Este importante patrimonio artístico había sido tratado por José Roda Peña, profesor de la Universidad de Sevilla y 
uno de los máximos especialistas en la escultura andaluza, como dejamos constancia en la valoración de su anterior libro sobre el escultor Pedro Roldán. Este historiador del arte ha dedicado estudios parciales al tema del paso procesional desde 1995, como el capítulo titulado «El paso procesional. Talla, dorado y escultura decorativa» incluido en la colección Sevilla Penitente y el artículo publicado en el año 2000 con el título "Retablos itinerantes», como esta publicación que comentamos. Aquellos estudios se han convertido en este trabajo exhaustivo de la evolución del paso procesional. El discurso se inicia con las primeras peanas o parihuelas documentadas en el último tercio del siglo XVI y termina con las cuatro cartelas que Mariano Sánchez del Pino ha realizado entre 2012 y 2014 para el paso de la agrupación parroquial de Pasión y Muerte, diseñado y tallado por el malagueño Manuel Toledano Gómez, que fue estrenado el Viernes de Dolores de 2009. Esta última obra es una demostración de que Roda Peña ha ampliado el estudio también a las procesiones que se desarrollan fuera del programa oficial de la Semana Santa durante el Viernes de Dolores y el Sábado de Pasión.

José Roda ha estructurado su trabajo en cinco amplias secciones que se desarrollan con un discurso cronológico, más un epílogo. La publicación lleva dos índices, uno de hermandades y otro de artistas, que favorece la búsqueda de temas concretos, que valoramos favorablemente porque actualmente no es habitual en las publicaciones de arte.

Roda Peña estudia la evolución del paso procesional analizando los contratos de los pasos desaparecidos y el análisis formal de los conservados, contextualizando las obras en la producción de cada artista, principalmente arquitecto-ensambladores, escultores, tallistas y doradores. En el primer capítulo se exponen las escasas noticias conocidas sobre las andas o parihuelas de estructura sencilla que servían para la procesión de las imágenes de Cristo en Semana Santa, que en ocasiones llevaron palio, según las descripciones del abad Alonso Sánchez Gordillo. También destaca la manera de trasladar el Cristo yacente de la Hermandad del Santo Entierro sobre los hombros de varios clérigos y sobre ellos un palio negro. Por último, este profesor analiza un dibujo de la primera mitad del siglo XVII que representa el paso de Jesús Nazareno de Sevilla.

De los pasos procesionales realizados en las décadas de 1650 y 1660 se analizan los contratos y los pagos, tanto parciales como finiquitos. El arquitecto-ensamblador Fran- cisco Dionisio de Ribas realizó el primer paso en 1651 para el popular Cristo de San Agustín. De las obras de esos años solo se conservan algunos restos de elementos escultóricos, entre los que destacamos los relieves de las cartelas del paso del Descendimiento de la Cofradía de la Quinta Angustia, que fueron tallados en 1659 por Pedro Roldán para un paso construido por el ensamblador Francisco Ramírez. En la década de 1660, el escultor Pedro Roldán aparece colaborando con otros arquitecto-ensambladores como Pedro Camacho de la Vega y Bernardo Simón de Pineda. Los pasos barrocos están configurados por un cuerpo de madera tallada con los lados convexos y con elementos ornamentales de hojarascas, caladas o no, tarjas, cartelas, etc., que se completan con escenas de la Pasión talladas en relieve y con la presencia de ángeles portando símbolos pasionistas.

El gran desarrollo creativo del paso procesional se produjo en la etapa artística sevillana denominada «Esplendor Barroco» o «Triunfo de la columna salomónica». Este fenómeno artístico tuvo un nexo común, la actividad de la Academia de dibujo que fundaron los pintores Bartolomé Esteban Murillo y Francisco Herrera el Mozo con la colaboración de otros artistas importantes, como Juan de Valdés Leal, Pedro Roldán y Bernardo Simón de Pineda. En la década siguiente, los autores de los pasos procesionales fueron los artistas de una generación más joven, como los arquitecto-ensambladores Cristóbal Guadix, Pedro de Soto y Cristóbal Pérez, y los escultores Francisco Antonio Gijón, Luisa Roldán, Luis Antonio de los Arcos, Miguel Franco, etc. Con frecuencia los contratos eran asumidos conjuntamente por un ensamblador y un escultor, como Guadix, La Roldana y su marido en el paso de la Exaltación y en el de las Tres Necesidades, de los que se conservan relieves y ángeles pasionistas. No obstante, Gijón fue el artista que mayor número de pasos contrató solo y el que, según la documentación conocida, aportó más novedades al diseño de estos retablos itinerantes: Cristo del Buen Fin de Triana (1677), cuya hermandad se extinguió en el siglo XVIII, Niño Jesús de la Cofradía del Dulce Nombre (1677), Jesús de las Tres Caídas de la parroquia de San Isidoro (1687), Despredimiento (1688), Gran Poder (1688) y Cristo del Amor (1694-1695), siendo estos dos últimos los conjuntos mejores conservados del siglo XVII. En algunas ocasiones, las cofradías han vendido sus canastos a otras ciudades o pueblos: la Hermandad de las Tres Necesidades de la localidad cordobesa de Cabra posee los ánge- 
les pasionistas que Pedro Roldán hizo en 1674-1677 para el Cristo de la Conversión, y la Hermandad del Santo Entierro de Carmona conserva los relieves que ese mismo escultor talló entre 1686 para el paso del Nazareno de la O de Sevilla.

El tercer capítulo se titula «La difusión del paso barroco» y está dedicado al siglo XVIII, en cuyo periodo se realizaron nuevos pasos procesionales (el anónimo de la Mortaja, 1710-1711; Antonio José de Carvajal hizo los de la Hermandad de la Vera Cruz, 1713, etc.), y algunos pasos existentes se transformaron, como el de Jesús Nazareno del Silencio, o se les añadieron ángeles, como los que Benito de Hita y Castillo incorporó al canasto de Jesús del Silencio ante el Desprecio de Herodes (1763).

En el cuarto capítulo se analizan las constantes crisis y reorganizaciones que las cofradías sufrieron durante el siglo XIX, repercutiendo en la renovación de los pasos. Esa situación se inició a finales del siglo XVIII, cuando el rey ordenó la reducción de las asociaciones religiosas y la primera pérdida patrimonial importante comenzó con la desamortización francesa. La recuperación producida después durante el primer tercio del siglo permitió que la nueva estética neoclásica, impuesta por el oficialismo académico, se reflejara en los nuevos pasos procesionales, como el del Santo Entierro diseñado por Melchor Cano y tallado por Lucas de Prada (1827-1830). No obstante, la depuración formal había comenzado años antes con el paso de la Coronación de Espinas (1801) que talló Juan Calero bajo los postulados clásicos y lo doró Cristóbal Vázquez.

En ese siglo comienzan los ensayos de diseño incorporando elementos clásicos (columnas, frontones triangulares, etc.) y los lados cambian la curvatura barroca por estructuras simplificadas de cuarterones planos (Entrada de Jesús en Jerusalén, Exaltación, Jesús de la Salud de la Hermandad de los Gitanos, Oración en el Huerto, etc.). A comienzos del tercer tercio del siglo los estilos historicistas imperantes en la arquitectura religiosa también tuvieron reflejo en el diseño de los pasos, incorporándose doseletes ojivales, arcos apuntados, baquetones y pináculos. El artista Juan Rossy, el pintor Antonio del Canto, el escultor Manuel Gutiérrez Reyes, José de la Peña, entre otros, fueron los autores de esta renovación estética. El primero fue autor del nuevo paso del Santo Entierro y de la alegoría del Triunfo de la Santa Cruz, dos de las mejores obras de ese siglo. Estos estilos no se produjeron en tiempo consecutivo, sino simul- táneos a la corriente neobarroca, como la reforma de José de la Peña en el paso del Nazareno de la O; el paso que hizo primero Antonio Montero y después Juan Rossy para Jesús de la Pasión; el que Antonio del Canto y Juan Rossy tallaron para el Descendimiento de la hermandad de la Quinta Angustia; y, entre otros, el que José Vicente Hernández y José Ríos tallaron para el grupo escultórico de la Sentencia. Los diseños de los pasos de la Edad Contemporánea han perdido la unidad estética de los siglos del Barroco.

El cambio de los gustos estéticos provocará que los responsables cofrades, sin una conciencia conservadora del patrimonio cultural, decidan durante el siglo $X X$ renovar sus pasos, lo que unido a la aparición de nuevas cofradías generará una importante producción para satisfacer la demanda sevillana, en la que intervinieron arquitectos, escultores, tallistas, doradores y plateros. Las formas, los elementos ornamentales, la policromía y los dorados, o sin ellos, se diversifican ampliamente produciéndose una disparidad de estilos personales, como magistralmente describe y analiza el profesor Roda Peña en el quinto capítulo del libro. No obstante, existe un número elevado de canastos dorados en los que predominan las plantas sinuosas, los laterales convexos y la ornamentación de hojarascas de talla menuda, muchas de ellas caladas, como derivados de los realizados por Francisco Antonio Gijón a finales del siglo XVII. El éxito de los nuevos modelos neobarrocos hará que sean demandados por las cofradías de otras ciudades y pueblos andaluces. Roda Peña analiza la producción de 37 artistas contemporáneos como autores de «La nueva Edad de Oro del paso procesional», unos diseñando, otros construyendo y otros dorando, entre cuyos nombres destacamos Antonio Castillo Lastrucci, José Merino Román, Juan Pérez Calvo, Rafael Fernández del Toro, Manuel Guzmán Bejarano, Antonio Vega, Antonio Martín Fernández, Antonio Joaquín Dubé de Luque, etc.

En el epílogo, José Roda trata de los pasos de Cristo que presentan la excepción de incorporar materiales metálicos. La madera y el bronce se combinan en el canasto del Descendimiento de la cofradía de la Quinta Angustia (19011904) en el que intervinieron varios autores: diseño de Pedro Domínguez López, modelos de José García Roldán y Emilio Bartolomé Lerma y fundición de la Casa Masriera y Campins. Aunque habitualmente la plata está reservada a los pasos de palio, existen dos de imágenes de Nazarenos que están realizados en este noble metal, como el de Jesús de 
la Pasión que el platero Cayetano González hizo entre 1943 y 1949, y el del Jesús Nazareno de la Divina Misericordia (1976-1987), obra del taller Viuda de Villarreal.

El libro ha sido editado por la Diputación de Sevilla siguiendo el magnífico programa de publicaciones que lleva a cabo dicho organismo, especialmente desde hace medio siglo. A la centenaria revista Archivo Hispalense, el organismo provincial incorporó en 1972 la colección Arte Hispalense dedicada a biografías de artistas y temas monográficos de carácter divulgador sin anotaciones científicas o aparato crítico. Hace unos años ese programa se incrementó con una nueva colección de Monografías de Arte, que llevan el adecuado aparato crítico y una extensión más amplia, en el que está editado este libro de 342 páginas de diseño clásico ilustrado profusamente con 145 fotografías, la mayoría a color, que se combinan con las reproducciones en blanco y negro de los antiguos pasos procesionales. Sin duda, esta publicación es un modelo a seguir por otros historiadores del arte para el estudio de esta modalidad artística en otras ciudades, aunque gran parte de la zona oriental de Andalucía perdió los antiguos pasos procesionales o retablos itinerantes.

José Luis Romero Torres

Consejería de Cultura. Junta de Andalucía 